\title{
Surgical Workload From An Integrated UK Field Hospital During The 2003 Gulf Conflict
}

\author{
DA Rew, J Clasper, G Kerr
}

\begin{abstract}
Aims

This paper reports the surgical experience of a UK reserve field surgical hospital during military operations in Iraq during March and April 2003. Particular reference is given to the integration of the surgical specialities, consultant led and multidisciplinary teamworking in the treatment of military and civilian casualties from all sources and of all causes.
\end{abstract}

\section{Methods}

All surgical workload data was collected prospectively for the warfighting (Phase One) and specialist referral (Phase Two) phases of the operation. Standard military and Red Cross protocols were used for all injuries and microbiology studies were undertaken for penetrating ballistic injuries. Operations were classified by anatomical region; upper or lower limb; head and neck; thoracic; abdominal, including genitourinary; ophthalmic; and burns, and by whether they were primary; secondary planned or secondary unplanned.

\section{Results}

A wide range of patterns of wounding arising from combat and non-combat related military and civilian trauma and burns were seen and treated. 323 operations were performed. There were 116 operations in phase one and 207 operations in phase two. There were 160 primary procedures (new patients), 146 secondary planned and 17 unplanned procedures (range one to eight procedures per patient).

Close integration of general, orthopaedic, plastic, maxillofacial, ophthalmic and neurological surgeons and general and ITU anaesthetists allowed the delivery of a range of specialist treatment to a heterogenous patient population, including children as young as 6 months and a lady in the advanced stages of pregnancy.

\section{Conclusions}

Patterns of wounding in casualties surviving to reach specialist field hospital care were similar to those reported in other high intensity conflicts. A consultant led, multidisciplinary approach with field intensive care facilities allowed combined, staged and safe surgery for complex, multi-organ and multi-limb trauma in an austere environment.

\section{Introduction}

The provision of surgical care is an age old challenge during war. Military surgery is conducted in a difficult and dangerous environment. There are often long delays in evacuation; multi-system trauma, wound contamination and adverse climatic conditions. Care must nevertheless be delivered to the highest contemporary standards consistent with the circumstances of war.

The many issues arising from further surgical specialisation in civilian practice have been a particular concern to military planners in recent years. Diverse practice and broad experience was the mainstay of military surgery during the last century. Subspecialisation is reducing the number of broadly trained surgeons able to deal with trauma and disease in a range of organ systems. Integration of surgical teams with a range of subspeciality skills might thus compensate for this fragmentation and enhance collective capabilities.

The British Army is currently supported by a cadre of regular and reserve consultant surgeons and anaesthetists and trainees drawn from military and NHS hospitals. They have a wide range of military and professional expertise and are trained to a common but adaptable treatment doctrine. This incorporates the principles of trauma management expounded by the International Committee of the Red Cross (ICRC). This doctrine has been supplemented in recent years by common training courses such as the definitive surgical trauma skills course run at the Royal College of Surgeons of England; the war surgery, bone and neurosurgical trauma workshops.

The Gulf conflict in 2003 involved a rapid move into Southern Iraq by UK forces. 202 Field Hospital was deployed to Northern Kuwait to provide surgical care for all casualties. In this paper, we report the surgical workload of 202 Field Hospital, with special reference to the integration of the surgical specialities to provide effective care of complex trauma. 
Organisation, Patients and Methods

202 Field Hospital is a reserve, cadre-ised unit of the UK Defence Medical services. Staffing for this deployment was principally of civilian reservists mobilized within three weeks of the commencement of hostilities, with no collective training prior to convocation at the war location. This group represented a wide and heterogenous clinical, managerial and military experience. Manpower was supplemented by a small regular command element and by regular service clinical specialists.

202 Fd Hosp was deployed to Northern Kuwait in mid March, a few days before hostilities began, as part of a matrix of land based, seaborne and mobile surgical elements in support of military operations. It was housed largely in tents and sited in open desert. It comprised eight wards with 200 beds and a six bedded intensive care and high dependency unit. Two containerised modular operating theatres were reserved for neurosurgery and had minimal operational use. All other surgery was carried out using four field operating tables set up in two tented operating theatres.

The hospital design allowed for rapid and logical casualty flow from arrival. The Accident, Emergency and Resuscitation department was immediately adjacent to theatres, with resuscitation teams supervised by an A and E consultant. Patients could be assessed immediately, augmented with mobile ultrasound and Xrays, and transferred to the operating theatre within minutes if appropriate.

\section{Field Intensive Care}

An important new feature of this deployment was the use of a fully functional field intensive care unit, with a capacity for up to 10 beds in a tented ward, and modular, portable equipment. This substantially extended the capability for the care of major trauma and severe burns cases, pre and postoperatively, and by permitting interrupted, staged, damage control and resuscitative procedures.

\section{The Population at Risk (PAR)}

The hospital was to provide care for some 50,000 coalition combatants, for captured Iraqi troops, and for civilian casualties from the population of 1.3 million people, where Iraqi civilian services were not immediately available.

\section{Casualty Inflow}

Casualties were delivered directly by a combination of coalition helicopters and wheeled ambulances. Casualty flow throughout the campaign, and particularly in the second phase, included a significant number of Iraqi civilians discharged from civilian hospitals on expectant treatment or unable to secure local hospital admission. A number were staged through other coalition medical facilities.

\section{Routes of Casualty Evacuation}

Casualty evacuation was perhaps the single most challenging issue of the deployment. Coalition service personnel could usually be evacuated rapidly and efficiently to UK or US home facilities by air. A small number of severe Iraqi burns cases were also evacuated to the UK after administrative, political, humane and Geneva Convention issues had been addressed.

There were severe constraints on the use of Iraqi civilian hospitals until late April, and special administrative considerations applied to the care of military prisoners of war and to the repatriation of Iraqi civilian patients under the Geneva Conventions. A particular anomaly was that many Iraqis could not be repatriated North across the Kuwaiti border despite their wishes and those of the hospital staff, because the International Red Cross was not satisfied with the care facilities in place in Iraq. $202 \mathrm{Fd}$ Hosp was thus rapidly adapted as a Role 4 hospital for the specialist care of these patients from across the area.

\section{Phases of Clinical Activity}

\section{Phase One}

The first phase of hospital activity took place between March 20th and March 31st, during which all battle casualties were received. This phase coincided with the peak intensity of warfighting.

\section{Phase Two}

In the second phase, between 1st and 30th April 2003, the task of 202 Fd Hosp was to provide the further specialist care of battle casualties and of civilian trauma of various types, including specialist treatment for patients unsuitable for further evacuation. 34 Field Hospital was deployed further forward as the primary casualty receiving unit during this phase, which coincided with peace making in the area of responsibility to the cessation of hostilities on 1st May and beyond. Most casualties during phase one arrived by helicopter, and by wheeled ambulance in phase two.

\section{Environmental factors}

Daytime temperature varied from 28 to 42 degrees centigrade in the tents without air conditioning. High ambient temperatures affected the performance of radiological and monitoring equipment. Weather conditions included rainstorms, frequent sandstorms and high winds. This created a dust hazard within tented theatres.

\section{Consultant Manpower}

Surgical teams comprised three reservist general and six orthopaedic surgeons, including paediatric experience, recruited 
from NHS hospitals around the UK. The hospital also had attached specialist teams of two reservist neurosurgeons and two plastic, one ophthalmic and one maxillofacial consultant surgeon from the Regular Army, with trainee support. There was no specialist obstetrician.

The consultant surgeons are listed at the end of the paper. There were 20 anaesthetists with a wide range of specialist skills, including two ITU anaesthetists. Surgical teams were supported by a full complement of operating theatre and nursing staff, radiology with image intensification, and laboratory support, including blood transfusion and microbiology. There was no histopathology support, and service personnel with even minor cutaneous lesions had to be evacuated out of Theatre for diagnostic biopsies.

\section{Results}

All data were collected prospectively by all surgeons and conventional theatre logs were used. Theatre log data was later transferred to an Excel spreadsheet. Formal statistical evaluation was not necessary.

160 new patients underwent 323 operative procedures at this hospital. These were classified as Primary Operations, Secondary Planned Operations, which included soft tissue cover procedures, repeat debridements and routine burn dressings and Secondary Unplanned Operations, for reasons such as wound infection, haematoma and adjustment of external fixators (Table 1).

\begin{tabular}{|l|l|l|}
\hline & Phase 1 & Phase 2 \\
\hline Casualties received & 82 & 78 \\
\hline Primary procedures & 82 & 78 \\
\hline Secondary Planned & 28 & 118 \\
\hline Secondary Unplanned & 6 & 11 \\
\hline Total operations & 116 & 207 \\
\hline Total procedures & 163 & 220 \\
\hline
\end{tabular}

Table 1. Breakdown of procedures by phase and classification.

\section{Phase One}

Eighty-two casualties underwent 116 surgical procedures under general anaesthesia during this phase. The surgical casualty flow never exceeded our maximum capacity, and at busy times, surgeons worked on a cab rank principle, sharing skills and experience as appropriate.

There were 21 procedures performed on Allied personnel for trauma and 10 nontrauma cases such as drainage of abscess. There were 46 trauma related procedures on Iraqi combat personnel, 30 on Iraqi civilian adults, and eight on Iraqi civilian children (aged between six months and 16 years). There was one elective operation unrelated to trauma.

During phase one, a number of patients were received from forward surgical teams with augmented Role 2 units known as Role $2+$ units, equipped and briefed to resuscitative conduct damage control surgery. Patients received included two casualties who had undergone laparotomies, and patients with complex limb injuries who required further reconstructive procedures.

\section{Phase Two}

There were 220 surgical procedures under 207 general anaesthetics. There were 9 procedures on Allied personnel for trauma and 10 non-trauma related procedures. There were 79 on Iraqi combat personnel, 55 on Iraqi civilian adults and 51 on Iraqi civilian children. There were 3 elective procedures on Iraqi adults, unrelated to trauma.

This caseload comprised 78 primary operations on new patients from all sources; 118 Secondary Planned Operations; and 11 Secondary Unplanned Operations. The phase two patients included specialist referrals from UK role two treatment units $(n=5)$; from the other UK hospital units $(\mathrm{n}=17)$; from Iraqi civilian hospitals and other sources $(n=20)$, and direct admission $(\mathrm{n}=36)$.

Thus, 160 new patients (82 Phase one, 78 phase two) underwent 323 operative procedures, reflecting the large volume of burns dressing and staged orthopaedic procedures in particular in Phase two.

\section{Classification and patterns of injuries}

Penetrating ballistic injuries were classified according to the site of injury, as upper and lower limb; neurosurgical; head and neck; thoracic, abdominal and ophthalmic. It was found unhelpful to classify operations by the speciality interest of the operating surgeons, as many procedures were undertaken jointly for multiple and complex wound patterns.

It was often difficult to determine the precise mechanism of wounding in patients of ballistic trauma, but some $25 \%$ appeared to be due directly to bullets and the remainder by shrapnel fragments. Torso injuries from high energy direct transfer weaponry were not seen, as these are usually immediately fatal, but high energy transfer wounds to limbs were survivable and recognisable by small entry but large exit wounds, and comminuted long bone fractures.

Blast was another cause of severe injury, often seen in association with penetrating fragments. Blast injuries included traumatic amputation from land mines, and severe damage to eyes.

Burns created a substantial workload. Patients included those associated with military operations and domestic and electrical accidents among the civil population, including small children. One lady in the late stages of pregnancy (7 months +) required a lower limb amputation. Perhaps fortunately, she did not 
deliver during treatment or before repatriation

\section{Multiple wounding}

The proximity of all surgeons allowed patients with injuries of more than one limb or anatomical region to be treated simultaneously or sequentially under one anaesthetic. During phase one, 116 patients underwent 163 separate regional operations, an average of 1.5 major injuries per patient. Many patients had multiple and superficial penetrating injuries from small, low energy fragments which required minimal debridement or conservative treatment and which were not included with these scores.

\section{Caseload and key management points by anatomical region}

\section{Limb injuries}

Most penetrating wounds were managed by exploration and wound excision. Minimal skin excision was usually required but a generous excision of muscle was carried out, particularly for high-energy transfer wounds. Wounds were extended in the longitudinal axis of the limb and fasciotomies carried out if appropriate. Bone fragments were removed if there were no soft-tissue attachments and the wounds were copiously irrigated. All fractures and extensive soft-tissue injuries were stabilized using plaster, traction or external fixation when appropriate.

Following surgery, all wounds were managed by delayed primary suture (DPS), usually at 5 days after the initial procedure. Extensive and heavily contaminated wounds were managed with wound inspection and further washout at 48 hours, prior to DPS at 5 days. Most wounds were closed by suture. A few required split skin grafting and six local muscular or fasciocutaneous flaps were raised.

A small number of wounds were managed conservatively, if they were superficial, associated with a small skin wound and with no clinical evidence of deep tissue damage.

\section{Abdominal and genitourinary trauma}

\section{Laparotomies}

No high energy transfer abdominal injures were seen at the Field Hospital. We received two patients who had undergone exploratory and negative laparotomies by Role 2 surgical teams, and one who had undergone DCS type surgery for severe injuries to the upper abdomen, who died soon after transfer.

We undertook two delayed laparotomies after observation, one in a soldier who had a slowly progressive haemoperitoneum from a small penetrating liver fragment, and one in a young child who developed progressive peritonism from small bowel perforations from a small low energy fragment. Both made uneventful recoveries.

One teenager underwent successful reconstruction and primary suture of a severely disrupted scrotum from a penetrating missile with testicular fragment preservation but unknown functional outcome.

\section{Chest Injuries}

Most patients with chest injuries were managed non-operatively with chest drains if appropriate. One thoracotomy for deep intrapulmonary haemorrhage was unsuccessful in a severely shocked patient.

\section{Maxillofacial patients}

We saw a range of injuries to the face, including nose, maxilla and mandible. These included missile fragments, blunt injury and burns. Management followed conventional practice, by immediate reduction and bony fixation, including interdental wiring. Associated eye injuries were managed concurrently. Particular attention was paid to airway management. Two tracheostomies were raised, one for facial burns and one for mid-facial trauma. Two casualties underwent immediate facial reconstruction for severe tissue disruption.

\section{Neurosurgical patients}

Four penetrating head wounds were explored by craniotomy, debridement and primary closure. One patient with a severe penetrating wound was managed expectantly and died within six hours.

\section{Ophthalmic patients}

Ophthalmic injuries were a mix of blast, penetration and corneal abrasion, the latter frequently arising from during severe dust storms. Most ophthalmic trauma was dealt with on an outpatient basis. Three patients underwent surgery as combined procedures in phase one, and three as single procedures in phase two.

\section{Burn patients}

Sixty casualties were seen with burn injury, including military flash burns and domestic heating accidents among civilian adults and children, affecting from $<1$ to $85 \%$ body surface area. 14 of these had suffered injury requiring formal intravenous fluid resuscitation. Mean burn size was $12.5 \%$. All patients underwent initial debridement, with escharotomy and fasciotomy where clinically indicated.

The initial plan to receive, treat and evacuate all casualties within 48 hours foundered when significant numbers of local population burn casualties were received. Although this remained the pathway for coalition casualties, for non-coalition casualties a decision had to be made regarding suitability for definitive 
management in theatre. Those evacuated had a combination of extensive burns requiring complex reconstruction or intensive care management where there was clearly going to be a prolonged in-patient period. The remainder were managed at this unit either conservatively or by excision and grafting as appropriate. Graft take was generally satisfactory. Burns treatment placed a significant burden on the unit, with a range of 1-13 procedures for each casualty.

\section{Paediatric caseload}

Paediatric workload arising from trauma to Iraqi children and teenagers was significant. 15 children aged 10 or under, including 3 babies under 18 months, and 9 teenagers aged from 11 to 16 underwent operations for a variety of injuries, including burns, abdominal, limb and multiple trauma. The hospital was not initially equipped or resourced for paediatric anaesthesia or surgery, but combination of improvisation and local sourcing allowed all to be managed safely.

The hospital was not staffed specifically for paediatric surgical specialists, but the seniority and breadth of civilian anaesthetic, surgical, technical and nursing skills permitted their safe management. The intensive care facility was particularly important in the care of these children, many of whom required multiple serial procedures.

\section{Combined, plastic and multidisciplinary} patients

A particular feature of the deployment was the facility for cross disciplinary teamwork, for example in respect of complex musculoskeletal injuries and severe multi-fragmentary ballistic fractures with significant soft tissue loss (Table 2); vascular injuries associated with soft tissue loss and / or fractures; burns, maxillofacial, neurological and ophthalmic patients.

\section{Examples of the integrated approach to case management}

Case 1. A soldier sustained penetrating wounds to the abdomen, buttock and right lower leg with an open fracture. Surgery at role $2+$ consisted of a limited laporotomy, debridement of the buttock and debridement and provisional stabilisation of his right leg with an external fixator. Surgery at Role 3 consisted of a fasciotomy of the right leg, revision stabilisation and closure with a lateral gastrocnemius flap and skin grafting. Delayed primary suture of the buttock was carried out after five days, following which he made an uneventful recovery.

Case 2. A soldier suffered a penetrating right shoulder wound, a superficial abdominal wall wound and a penetrating head wound. Exploration of the abdominal wound was carried out at Role 2. At Role 3, the shoulder wound was debrided by the orthopaedic team and the head wound by the neurosurgical team. All wounds healed without complication.

Case 3. A soldier sustained a massive fragment injury to the face, which was primarily reconstructed and the residual cavity packed. A tracheostomy was raised for facial burns. A rotational scalp flap was raised to cover tissue loss, and multiple corneal and lid lacerations were sutured by the ophthalmic surgeon.

Case 4. A teenage boy sustained multiple gunshot wounds to his right arm, superficial chest, both groins, including the femoral veins, and his left leg. Life saving surgery at role three included ligation of both femoral veins without wound closure prior to stabilization on ITU. Further surgery included removal of a bullet from his intercostals space, debridement and later closure of his left tibial fracture and both groins. Following infection of the right groin, later closure was achieved with a sartorius flap and split skin grafting. Subsequent recovery was uneventful.

\section{Combined acute limb shortening procedures}

Five patients, including one child of three years, underwent combined plastic and orthopaedic procedures with acute limb shortening of between two and four cms to achieve bone stability to facilitate soft tissue repair following severe bone and soft tissue loss. Two were closed with muscle flaps and split skin grafts; one with a fascio-cutaneous flap and one with split skin graft alone. The latter patient was also eight months pregnant.

\section{Operating times and theatre occupancy}

Operating times varied considerably with the scale of the procedure. There were 68 cases recorded as taking 100 minutes or more, including: 53 operations of between 100 and 180 minutes; one case of multiple injury in a coalition soldier taking 450 minutes; and the remainder taking between 180 and 270 minutes.

Theatre occupancy fluctuated considerably between one and four tables, but resources were never stretched to the point of causing unplanned delays in surgical care. During the second phase, the burns workload mandated the full resources of at least one table daily.

\section{Wound infection and bacteriology}

Samples of tissue were sent for conventional bacteriology on selected patients showing clinical evidence of infection. Species of common infecting organisms identified included Staph Aureus, common environ- 
mental organisms (Actinobacter spp) and pathogenic Gram Negative Bacilli, including Enterobacter Cloacae, Serratia and Pseudomonas spp. Unlike previous conflicts in different environments, Anaerobic Bacillae were not isolated, although Clostridial spores were isolated from environmental samples. MRSA was also isolated from one case of wound infection referred from another hospital.

\section{Follow up}

Long term follow up of most patients will not be possible because of the nature of our population. All Iraqi casualties were kept in hospital until wounds were fully healed, or until satisfactory arrangements could be made for their repatriation to Iraqi civilian facilities or through the ICRC.

\section{Deaths}

There were four trauma related deaths within the hospital. They included one soldier with multiple chest and abdominal trauma and one patient in a moribund condition with an open abdominal wound following damage control surgery at Role 2 and helicopter transfer. One soldier died during thoracotomy immediately after arrival following a pre-operative hypovolaemic cardiac arrest. A 4th patient with a penetrating head wound and extensive damage to both cerebral hemispheres, was managed expectantly.

\section{Discussion}

\section{Clinical workload}

Our reported casemix is consistent with the experience in other conflicts (1-5). Those casualties surviving to hospital care will inevitably be a fortunate and self selecting group, with a high chance of survival if offered competent care. War also poses a significant risk to non-combatants and civilians of all ages, and military planning must take into account the immediate surgical treatment and subsequent care and repatriation of significant numbers of casualties, including young children and women and expectant mothers.

Our Phase One population of Iraqi casualties exhibited a range of complex wounds which were characterised by survivability and a preponderance of penetrating limb trauma (Table 2). Our Phase Two population was almost entirely composed of Iraqi nationals as specialist referrals from other hospitals, including the late consequences of trauma, and domestic burns. Further evacuation of local nationals was initially not possible and we thus had to act in a base hospital capacity for these patients. This population was highly selected and we do not know if it was representative of patterns of injury in general among the population at risk.

\section{Organisational issues}

The introduction of a field intensive care unit with a full range of supportive and rescuscitative facilities contributed substantially to the successful management of a number of our complex cases. For example, it allowed interrupted, staged debridement of major injuries with concurrent resuscitation, a concept known as Damage Control Surgery (6-9).

A field ITU capability also creates a new demand on resources, as patients who would have otherwise died or have been deemed to be beyond treatment now survive. For example, patients with burns substantially in excess of $30 \%$ body area and who had reportedly been turned away from underresourced civilian facilities posed a substantial demand on our resources during their subsequent care.

\begin{tabular}{|l|l|l|l|l|l|l|}
\hline & $\begin{array}{l}\text { Phase } \\
\text { One }\end{array}$ & & $\begin{array}{l}\text { Phase } \\
\text { Two }\end{array}$ & & \\
\hline $\begin{array}{l}\text { Site of } \\
\text { Injury }\end{array}$ & $\begin{array}{l}\text { One } \\
\text { Cnslt }\end{array}$ & $\begin{array}{l}2 \text { Cnslts } \\
\text { same } \\
\text { speciality }\end{array}$ & $\begin{array}{l}2 \text { Cnslts } \\
\text { different } \\
\text { specialities }\end{array}$ & $\begin{array}{l}\text { One } \\
\text { Cnslt }\end{array}$ & $\begin{array}{l}2 \text { Cnslts } \\
\text { same } \\
\text { speciality }\end{array}$ & $\begin{array}{l}2 \text { Cnslts } \\
\text { different } \\
\text { speciality }\end{array}$ \\
\hline Upper Limb & 28 & 10 & 4 & 27 & 3 & 9 \\
\hline Lower Limb & 43 & 21 & 9 & 71 & 7 & 8 \\
\hline Cranium & 0 & 3 & 0 & 1 & 0 & 1 \\
\hline $\begin{array}{l}\text { Face and } \\
\text { Neck }\end{array}$ & 6 & 1 & 4 & 8 & 0 & 1 \\
\hline Eyes & 0 & 0 & 3 & 3 & 0 & 1 \\
\hline Burns & 15 & 0 & 2 & 61 & 3 & 0 \\
\hline Thoracic & 4 & 1 & 1 & 5 & 0 & 0 \\
\hline Abdomen & & & & & & 0 \\
\hline And GU & 7 & 0 & 1 & 10 & 1 & 20 \\
\hline Total & 103 & 36 & 24 & 186 & 14 & 20 \\
\hline
\end{tabular}

Table 2. The caseload of surgery during phase one and phase two, classified by the site of injury and by multi-consultant and multi-disciplinary patients. A number of patients had injuries of multiple anatomical regions treated under one anaesthetic. 
Specialisation and military surgical skills

War and conflicts will continue to produce a need for surgeons able to work to high standards in testing environments and to undertake a broad range of procedures. Over the past century, and particularly since the Second World War, there has been progressive specialisation in trauma management, for example, in the separation of general and orthopaedic surgery. This process continues across the surgical skills spectrum.

Modern armies are unable to train and retain all of the specialist surgical personnel in peacetime who are needed to provide cover and to meet modern expectations in wartime. They must call upon civilian reservists as needed. Changes in civilian training and specialisation are thus bound to affect the engagement and deployment of militarily useful surgeons. For example, senior and broadly trained general surgeons with competence in vascular, thoracic, abdominal, head and neck and urological surgery will be less commonly found, and there will be greater dependence upon larger teams of subspecialists. Indeed, the current generation of full time employed military surgeons are also trained principally in civilian hospitals in the UK, and are affected by the same considerations of subspecialisation.

The continued and appropriate training of surgeons to provide appropriate care for combatants and non-combatants in war is essential. Future UK military deployments will be supported primarily by surgeons training and working in civilian hospitals. Civilian clinical and technical skills will need to be supplemented by education and training in the specific doctrines and experiences of military surgery, which might include formally accredited courses, distance learning aids and pre-deployment refresher courses. The successful integration of the 202 Field Hospital staff, including the surgical teams, testifies to the effectiveness of such common training strategies and to the flexibility and adaptability of individuals from diverse professional and geographic backgrounds.

Military surgery also makes specific personal demands on individuals, who must be able, adaptable and prepared to work in austere conditions under military discipline and as teams. These skills and teambuilding need to be honed through regular military training and operational deployments, which make demands on specialist training and practice, and on the goodwill of civilian employers and colleagues. Our experience highlights the particular value of integration of specialist skills at consultant level in such circumstances, where the aggregation and proximity of expertise allowed a broad range of safe, complex, staged and multidisciplinary procedures to be conducted over four weeks of casualty flow in an austere environ- ment. The collocation of plastic and orthopaedic teams in particular allows for complex reconstructive and revisional surgery for injuries involving soft tissue loss, with minimal delay.

In conclusion, we consider that our experience confers useful lessons and observations for surgical provision in future conflicts, and demonstrates that surgical and high dependency care can be delivered effectively in an austere environment in an era of progressive civilian surgical specialisation. It also illustrates how a UK reserve hospital, broadly staffed with experienced and well trained individuals, can be assembled and delivered at short notice and perform to high standards of clinical governance in the demanding circumstances of distant expeditionary warfare.

We argue for the proximity of skills, the team building approach to consultant working and the development of an esprit de corps which have served the Defence Medical Services well on this occasion and which might once again find a wider application in civilian hospitals. Expeditionary military operations have been a key feature of British history over the past millennium. We believe that our recent experience provides useful lessons for future planners to help reduce the morbidity and mortality of conflict.

\section{Acknowledgements}

We thank the commanding officer of 202 Field Hospital and the Ministry of Defence for permission to publish this experience, and our anaesthetic and theatre team colleagues for all their help. The opinions expressed are personal to the authors and do not necessarily represent official policy.

The contribution of the following consultants to the conduct of surgery and the collection of data is gratefully acknowledged. Civilian NHS hospitals (district) or Army Medical Services (AMS) status are indicated.

\section{Accident and Emergency Medicine: G Ward (Coventry)}

General Surgery: R Donaldson (Belfast), R Peyton (Dungannon), D Rew (Southampton)

Orthopaedic Surgery: J Clasper (Frimley Park), P Henman (Newcastle), V Kane (Nuneaton), G Kerr (Northampton), S Phillips (KCH London), G Rushforth (Salisbury)

Plastic Surgery: N Bennett, A Malyon (AMS)

Maxillofacial surgery: D Bryant (AMS)

Ophthalmic surgery: A Jacks (AMS)

Neurosurgery: C Shieff (Royal Free, London), P Stanworth (Coventry). 


\section{References}

1. Spalding TJW, Stewart MPM, Tulloch DN, Stephens KM. Penetrating missile injuries in the Gulf War 1991. Br F Surg 1991;78:1102-1104.

2. Bellamy RF. The causes of death in conventional land warfare: implications for combat casualty research. Mil Med 1984;149:55-62.

3. Bellamy RF, Manigas PA, Vayer JS. Epidemiology of trauma: military experience. Ann Emerg Med 1986;15:1384-1388.

4. De Wind CM. War injuries treated under primitive circumstances: experiences in an Ugandan mission hospital. Ann Roy Coll Surg Eng 1987;69:193-195.

5. Melsom MA, Farrar MD, Volkers RC. Battle casualties. Ann Roy Coll Surg Eng 1975;56:289-303.

6. Hirshberg A and Mattox KL (Eds). Damage Control Surgery. Vol 77 Issue 4. pp761-953 The Surgical Clinics of North America 1977.

7. Trunkey DD. Trauma. Sci Am 1983;249:20-227.

8. Eiseman B, Moore EE, Meldrum DR and Raeburn C. Feasibility of Damage Control Surgery in the Management of Military Combat Casualties. Arch Surg 2000; 135, 11:1323-1327.

9. Clasper J and Rew DA. Trauma life support in conflict. Brit Med f 2003; 327: 1178-79. 